Improving complex systems today : proceedings of the 18th ISPE International Conference on Concurrent Engineering, Massachusetts, USA 4-8 July 2011, pp417-424 Eds. Daniel D Frey, Shuichi Fukuda, Georg Rock.

\title{
Planning Manufacturing in a Concurrent Engineering Environment: A Case Study
}

\author{
Malachy Maginness ${ }^{\mathrm{a},}$, Essam Shehab ${ }^{\mathrm{b}, 1}$ and Chris Beadle ${ }^{\mathrm{c}}$ \\ ${ }^{\mathrm{a}, \mathrm{b}}$ Decision Engineering Centre, Manufacturing Department, Cranfield University, \\ College Road, Cranfield, Bedfordshire, MK43 0AL, United Kingdom \\ ${ }^{\mathrm{c}}$ Rolls-Royce plc., PO Box 31, Moor Lane, Derby, DE24 8BJ, United Kingdom
}

\begin{abstract}
This paper presents an investigation of current state practice of the Manufacturing Engineering discipline for concurrent manufacturing planning. The research adopted a case study approach and has been conducted at a globally operating manufacturer of aerospace products. The investigation establishes how information systems and the cross-functional teaming enable integrated processes for planning the manufacturing method to progress simultaneously with design in a lean and efficient manner. It applies value stream analysis to understand where value and non-value is added in these transactional processes.
\end{abstract}

Keywords. New Product Introduction, Manufacturing Engineering, Aerospace

\section{Introduction}

Robust New Product Introduction (NPI) business processes are crucial for conducting product development in complex engineering projects. The product development challenge of the aerospace industry lies in delivering high complexity product systems at the highest levels of quality. Legislative, environmental and economic factors compel product solutions to satisfy performance requirements in areas of fuel efficiency, emissions control and operating costs. In turn aerospace manufacturers are driven toward complex NPI projects with considerable technical challenges, development period and financial investment. The ability of manufacturers to deliver quality and cost effective products in a short time to market is a basic competitive requirement. As such, NPI processes must be suited

\footnotetext{
${ }^{1}$ E.Shehab, Manufacturing Department, Cranfield University, College Road, Cranfield, Bedfordshire, MK43 0AL, United Kingdom; Tel: +44 (0)1234 750111 x524; Email: e.shehab@scranfield.ac.uk
} 
to the requirements of Concurrent Engineering and be efficiently and effectively integrated across the product development supply chain. This research is conducted with the support of a globally operating manufacturer of aerospace products based in the United Kingdom. Here, NPI processes are administered across a matrix of business units and collaborating functions. The Manufacturing Engineering function is responsible for planning manufacturing and assembly methods that delivery product designs at levels of cost, quality and lead time that are consistent with customer requirements. The manufacturing planning challenge is delivering capable, multi-process manufacturing methods simultaneously with the development of the product solution by the Design Engineering function. The sponsoring company has adopted Concurrent Engineering in product development projects and has invested in integration practices and information system technologies to support the approach. These include examples of PLM (Product Lifecycle Management) and CAD/CAM (Compute Aided Design/Manufacture) software; cross-functional teams to manage component level NPI; and design for manufacture (DfM) dialogue. This study is motivated by a need to better understand the Manufacturing Engineering role and manufacturing method planning within Concurrent Engineering. Issues impacting Concurrent Engineering effectiveness include a 'hostile' downstream attitude to receiving unfinished design work that is likely to be changed, and the willingness of upstream and downstream parties to make agreement when determining a design [4]. By applying value stream mapping and analysis, this study seeks to understand the practices that enable such unfinished work to be used in NPI processes for planning the manufacturing method in the context of a large aerospace project.

\section{Related Literature}

A growing area of literature applies lean principles to transactional processes in product development [1, 3, 5-10]. Lean principles represent an extension of best practice in product development and add the efficiency concepts of value management to the principles of integrated problem solving. Existing integrated problem solving practice (Concurrent Engineering, cross-functional integration etc.) are congruous with application of lean in the product introduction. A criterion for identifying activities within a transactional process by value type (Directly Value Adding, Enablers of Value Adding activity, or Non-Value Adding wastes) is established for determining where value is added by activities within a value stream [9]. Furthermore, a methodology for value stream analysis of transactional engineering processes has been successfully demonstrated in the context of aerospace Design Engineering [5]. This research seeks to contribute to this field of inquiry and investigate current state processes for planning manufacturing method. 


\section{Method}

The case study was defined in three elements: the NPI processes of interest, the NPI project for which these were conducted, and the responsible business unit within the company. The work breakdown structure for NPI projects identifies distinct standard processes for planning the method of manufacture which are expected to interact with one another. The true nature of process interactions was revealed from the collected data. Case Study 1 examined processes dedicated to the development of tooling for a multi-process manufacturing method. Case Study 2 examined the design and manufacture of special work holding fixtures (tools required in the manufacturing method) from the point of receiving component definition through to tooling design and ultimate handover to shop floor operations.

The second and third elements of the case defined the context and reflect the complexity of the product development supply chain. Large product projects at the sponsor company are disseminated into individual component level NPI projects and are carried out in individual business units. Each case investigated, for a certain component from a contemporary project, how the NPI processes were carried out by the respective business. The same product project was selected for both cases. As the most immediately recent project it represents the state-of-the-art practice in the company. Data collection was assisted by the ready availability of project documentation and the continued presence of engineers involved.

The same data collection and analysis method was followed in each case. Group workshops with representatives from across the engineering disciplines were held at the start of each case. Post-it ${ }^{\circledR}$ Notes were the flexible and interactive means of capturing an initial high-level process description. A semi-structured interview was used for first-hand data collection and complemented a review of available project documentation. Interview candidates were selected from the management level of the relevant business unit through to component-level project managers and specialist Manufacturing Engineering resources that participated in the component NPI project in question. The question set was designed for one hour's interview length and was structured in accordance with two major concepts that are established in literature for understanding transactional processes. Opening questions follow the Supplier-Input-Process-Output-Customer (SIPOC) model and captured information inputs into activities, output information and the dependencies of other activities on these [2]. Secondary questions are developed from an existing value steam analysis question set [5]. This captured time metrics, governance concepts (disciplines involved) and tools used (software systems).

Process mapping and value stream concepts served as the analysis method. In each case, a map was created to depict how process activities were executed at component level. Activity boxes linked by arrows recorded the information flow of and the role-activity format allowed the association of a specialist discipline with activities to be seen throughout the process. Corroboration of interviewee accounts was made by examination of associated project documentation (including project plans), and validation of the findings in a concluding group workshop. 


\section{Findings}

Practices that enable manufacturing method planning to progress simultaneously with those of Design Engineering (model creation and analysis processes that determine the component form) are identified. This includes the integration support given by the information technology system tools and cross-functional teaming.

\subsection{Progressive Definition Release}

Quality manufacturing plans rely matching the design intent. Mechanisms of progressive definition and the application of 'surrogate' product information resolve the paradox of beginning manufacturing planning when final intent is determined later, at the end of the design process. 'Progressive definition release', describes how component information created by Design Engineering is integrated into Manufacturing Engineering processes. Both cases demonstrate how progressive information is integrated into the planning work stream. This enables planning to be executed concurrently with a continuing design effort. 'Buy-off' (formal agreement that a method matching design intent can be delivered) becomes a progressive process based on partial or incomplete definitions.

Progressive product information definitions that are useful inputs into buy-off and planning processes are identified. These allow manufacturing decision-making and resource planning (tools or materials ordering, especially those with long lead times) to advance to the extent that production trials are commenced ahead of final designs. The structure of the progressive definition modifies the medium (ranging from new sketches, sketches that modify past component drawings, CAD models and finally engineering drawings) in which product information (material, geometry or tolerances) is stated. This structure reflects the increasing maturity of the design. Accepting preliminary design information removes waiting from the project critical path. For example, certain upfront planning decisions (securing capital funds or long lead time orders) are based on sketches or 'design envelopes' (geometry limits known early). Later, geometry contained in CAD models is used to plan manufacturing methods ahead of detailed Engineering Drawings.

'Surrogate' information is used alongside incomplete product information to support buy-off and commence planning. This is based on past projects with comparable component geometry. Templates of information include a generic Method of Manufacture or 'router'. In its final form the Method of Manufacture documents the sequence of operations (including relevant processes and equipment) that transform raw material into a final shape. Design 'standards' is a mechanism to enable buy-off of preliminary definitions (sketches and models) with reduced risk. Geometry and tolerances that represent the best potential process capability are agreed upfront between Design and Manufacturing Engineering. Planning work progresses on the assumption that design geometry and tolerances will be defined consistent with agreed standards and will thus be compatible with planning definitions when completed. Cross-functional teaming is an important function of managing progressive release. In this team the Manufacturing Engineering representative (a Component Owner) sets out the requirements for and negotiates the schedule and structure of progressive definition release. 


\subsection{Planning Definition Driven from CAD Models}

Planning definitions are generated in a manner that is consistent with the Method of Manufacture sequence of manufacturing operations. Each stage of operation is defined in a Stage Model and Stage Drawing. Stage Models describe the component shape at the end of each operation. Stage Drawings define that model's geometry and specify details including work holding areas and datum points. The planning process and the definition of Stage Models is driven from the CAD model of the component design and are associated with that model's geometry. A single design model propagates numerous Stage Models and Stage Drawings. A range of downstream planning definitions derive from these. These include the design and manufacture of machine tools, production tools, work-holding fixtures, creation of NC (Numerical Control) machining and CMM (Coordinate Measurement Machine) sequences and creation of Manufacturing Instructions (technical information required by the operator to complete manufacturing operations). As such the process of creating the Stage Models and Stage Drawings interacts with the processes that define these downstream items. Using CAD models, rather than drawings, to generate planning definitions is crucial for integrating the planning processes and sharing product information. The PLM (Product Lifecycle Management) system employs consistent CAD software (UG-NX). Design and manufacturing information is stored and directly accessed on a shared environment for progressive release. Design and process planning models (Stage Models and downstream derivatives) are created in the same CAD application (Unified Graphics or UG/NX software). By using models within a consistent information system any revisions to the master design model can cascade through to the Stage Models and derivative planning definitions automatically with minimal rework or change management effort. In this way planning a quality manufacturing method, which is dependent on matching the design intent is supported. Integration within the PLM environment facilitates this. Process structure plays a role in managing the risk of rework or revisions to planning definitions. Limits to the downstream use of preliminary design model data are set within the process. Committing resources or investment in planning (e.g. to design and procure fixture tools) is suspended until the cross-functional team confirms certain geometry is fixed. Accordingly certain Stage Model and derivative definitions are protected from further revision in later updates and resources are thus invested with reduced risk.

\subsection{Appraisal of the Value Added in the Planning Processes}

Value stream analysis principles were applied to the mapped manufacturing planning processes [5, 9]. Direct Value Add activities are identified as those that define the product or process. Planning definition activities correspond with this; i.e. creating Stage Models, Fixture Models, NC Programming and manufacture/machining of tooling. Activities that reduce risk and uncertainty are also classed as value adding. Good quality simulation and method trials satisfy this. Enabler activities help form the value adding output. Stage Drawings, Tooling Drawings correspond to this and describe CAD model geometry in a manner that enables downstream planning, such as tooling fabrication to proceed. 


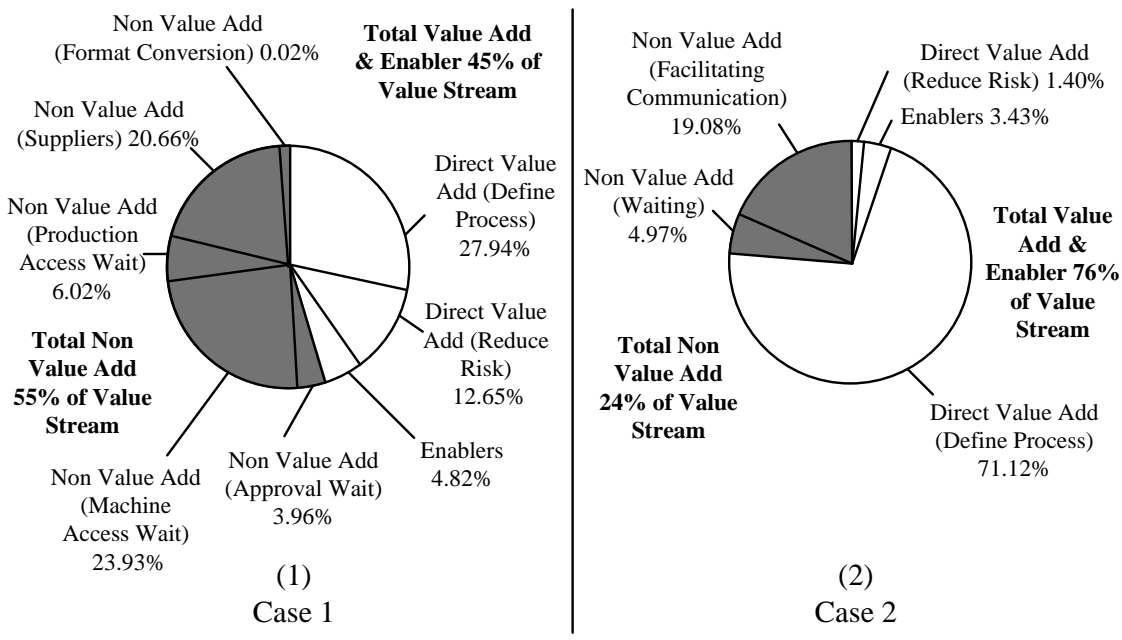

Figure 1. Value Stream Contributions in Cases $1 \& 2$

The forgoing analysis validates the activities of the current state processes that support the Manufacturing Engineering value proposition- the delivery of a quality and cost effective method of manufacture that matches the design intent. These are transactional processes aimed at making a physical shop floor process. It is possible to identify where non-value add, or waste exists. In Case 1 it is calculated that the direct value add and enabling activities contribute only $45 \%$ of the total value stream lead time (Figure 1-1). In Case 2 this is 76\% (Figure 1-2). Analysis of the waste types helps to understand proportions of the waste within the total lead time of the Manufacturing Engineering NPI processes.

Waiting is the significant feature of the value stream in both cases. The convention followed in analysis is that lead time for an individual activity is the sum of cycle time (pure working time) and waiting time (delays and interruptions). Waiting is identifiable with iterations of physical trials of the manufacturing method (Case 1), and the purchasing and tendering procedures (Case 2). In Case 1, the method planning is dependent on batch trials and altering the production tools with additional machining. Waiting time is encountered in trials when accessing plant equipment shared with other production areas. Machining of tooling used in the method encounters a similar wait. Waits are compounded by the iterations of trials required. Despite risk reduction activities being classified as 'value add' it is notable that the non-value add waiting component associated with trials accounts for $30 \%$ of the total lead time for delivering a quality method. Reducing dependency on physical iterations themselves with enhanced virtual simulation capability is an improvement opportunity. Additionally, the majority of the lead time for laboratory evaluation of parts produced by the trials is described as waiting. The laboratory requires upfront involvement in the project to ensure resources are available when required for such evaluation. The fixture tool design and delivery process investigated in Case 2 reveals additional wait aspects including interaction with purchasing and tendering processes. A significant 
contribution is made to lead time where Manufacturing Engineering processes interact with those of the purchasing function. Activities associated with purchasing and tendering are approximately $20 \%$ of the total lead time and lie on the critical path. These correspond to the non value add concept of facilitating communication. This 'non-value add' category endorses the view that communication should be seamless in lean processes [3]. Further waste is evident in the value streams. Transportation type waste is identified in the transfer of model data between information systems. These actions are 'breaks' in the integrated information system. Breaks are observed where alternative software and/or isolated PC systems are used outside of the PLM environment (i.e. nonPLM model data). This insulates downstream planning definitions from the design model. The cascade of updates is prevented which necessitates additional change management. The definitions propagated in this manner require manual intervention and updating in order to reflect changes to design intent.

In Case 2, the Manufacturing Engineering team made extensive and consistent use of the PLM system for creating and distributing planning definitions. Motion waste remains evident where physical transfer by hard drive media is necessary between computers running the standard PLM systems and separate stand-alone machines upon which preferred or legacy software exists. Similarly inconsistent file formats require conversion from an original model format (when created in the standard CAD software) and/or transferred to an alternate system.

\section{Conclusions and Future Work}

This paper reports two case study investigations of Manufacturing Engineering for New Product Introduction in the context of large aerospace product development. The practices enabling a quality manufacturing method to be planned and delivered within a Concurrent Engineering project approach are identified. The investigation into this area of product development decision making and the application of value stream analysis to the transactional processes, is the contribution of this paper.

The timing and structure of progressive release supports the conduct of planning processes such that ramp-up can occur in a manner that is simultaneous to the completion of design. This permits a greater window of opportunity for design to define the innovative product solutions that drive the competitive strategy in this industry. The decision-making observed here balances the factors of Quality, Cost and Delivery by using incomplete product information progressively received from design sources, and manufacturing knowledge from past projects. Furthermore, the work of planning definition is understood to propagate a range of specialist processes. Matching design intent throughout all these is a key aspect of delivering a quality manufacturing method. Driving planning processes from the design CAD model, through an integrated information system efficiently ensures quality.

Applying lead time metrics to the analysis of the product development value stream is a relevant approach. Reducing the time between decision-making events is critical for achieving a rapid and flexible NPI capability. Lean principles help the process more quickly arrive at decision-making events with lower uncertainly. The case studies reveal areas in current NPI processes where wasteful activity 
lengthens the lead time for the processes. The value analysis is quantitative data (lead time metrics) upon which improvement actions can be justified as necessary. These case studies have investigated discreet, component level facets of a large aerospace NPI project. The project complexity is manifested in numerous components and system families, all subject to NPI processes in a Concurrent Engineering manner. Further study shall seek to understand the complexity of managing numerous simultaneous NPI processes, and the application of information systems and the cross-functional approach to support Manufacturing Engineering and the quality of manufacturing method planning.

\section{Acknowledgements}

The authors would like to thank the sponsors, Rolls-Royce plc, the Decision Engineering Centre in the School of Applied Sciences at Cranfield University, and the Engineering and Physical Sciences Research Council for supporting this work.

\section{References}

[1] Baines T, Lightfoot H, Williams GM, Greenough R. State-of-the-art in lean design engineering: A literature review on white collar lean. Proceedings of the Institution of Mechanical Engineers, Part B: Journal of Engineering Manufacture 2006; vol. 220, no. 9, pp. 1538-1547,

[2] Browning TR, Fricke E, Negele H. Key concepts in modeling product development processes. Systems Engineering 2005; vol. 9, no. 2, pp. 104-128

[3] Chase J. Value Creation in the Product Development Process. Masters thesis, Massachusetts Institute of Technology, Cambridge, 2001.

[4] Clark KB, Fujimoto T. Product Development Performance: Strategy, Organization and Management in World Auto Industry. Harvard Business School Press 1991.

[5] Darwish M, Haque B, Shehab E, Al-Ashaab A. 2010 Value Stream Mapping and Analysis of Product Development (Engineering) Processes. Proceedings of The 8th International Conference on Manufacturing Research (ICMR 2010), University, Durham, UK, 14-16 September 2010.

[6] Haque B. Lean engineering in the aerospace industry. Proceedings of the Institution of Mechanical Engineers, Part B: Journal of Engineering Manufacture 2003; vol. 217, no. 10, pp. 1409-1420.

[7] Haque B, Moore MJ. Measures of performance for lean product introduction in the aerospace industry. Proceedings of the Institution of Mechanical Engineers, Part B: Journal of Engineering Manufacture 2004; vol. 218, no. 10, pp. 1387-1398.

[8] Liker JK, Morgan JM. The Toyota Way in Services: The Case of Lean Product Development. Academy of Management Perspectives 2006; vol. 20, no. 2, pp. 5-20.

[9] McManus H. Product Development Value Stream Mapping (PDVSM) Manual. MIT Lean Aerospace Initiative, Cambridge, 2005.

[10] Reinertsen DG. Let it flow. Industrial Engineering (American Institute of Industrial Engineers) 2005; vol. 37, no. 6, pp. 40-45.

[11] Reinertsen DG. The Principles of Product Development Flow: Second Generation Lean Product Development. Celeritas Publishing 2009. 